\title{
Equivalência e Processos de Referenciação na Construção Identitária do Movimento Occupy Wall Street
}

\author{
Equivalence and Referential Processes in the Identity Construction of the Occupy \\ Wall Street Movement
}

\author{
Thaysa Maria Braide de Moraes CAVALCANTE* \\ Universidade Estadual do Ceará (UECE) \\ Maria Helenice Araújo COSTA** \\ Universidade Estadual do Ceará (UECE)
}

\begin{abstract}
RESUMO: Este artigo objetiva empreender uma análise da construção identitária do movimento norte-americano Occupy Wall Street (OWS) em dois textos publicados no início do movimento, a partir de equivalências produzidas por meio dos processos referenciais. Para tanto, utilizamos a teoria do discurso proposta por Ernesto Laclau \& Chantal Mouffe, e da referenciação, na perspectiva de autores como Mondada \& Dubois, Marcuschi e Cavalcante, nos apropriando, sobretudo, da categoria sociodiscursiva de cadeia de equivalência e das categorias textual-discursivas de introdução referencial, anáfora e dêixis, as quais constituem os processos referenciais. Conduzidos por uma metodologia de análise qualitativa, chegamos à conclusão que o referente construído tende a funcionar, pelas equivalências que estabelece, como o significante de uma indeterminação, o que Laclau chama significante vazio. Apontamos para a importância de considerar a referenciação como um ato político e esquivarmo-nos de definições herméticas que desconsideram as múltiplas direções a que o processo referencial pode nos conduzir.
\end{abstract}

Palavras-chave: Discurso. Identidade. Processos de Referenciação.

\begin{abstract}
The aim of this article is to undertake an analysis of the Occupy Wall Street (OWS) movement's identity construction in two texts published at the beginning of the movement, from equivalences produced through referential processes. Therefore, we use the Theory of Discourse proposed by Ernesto Laclau \& Chantal Mouffe, And referencing, from the perspective of authors such as Mondada \& Dubois, Marcuschi and Cavalcante, and, above all in appropriating, of the socialdiscursive category of equivalence chain, and of the textualdiscursive categories which constitute the referential processes, referential introduction, anaphora and dexis. Conducted by a qualitative analysis methodology, we came to the conclusion that the referent built tends to work, by the equivalences that it establishes, as the signifier of an indeterminacy, what Laclau names empty signifier. We point to the importance of considering referencing as a political act and to avoid hermetic settings which disregard the multiple directions to which the referential process can lead us.
\end{abstract}

Keywords: Speech. Identity. Referential Processes.

\section{Introdução}

Apesar da aparente exaustividade no tratamento da questão da referenciação nos estudos linguísticos, muito há ainda a ser explorado, sobretudo quando consideramos a ampliação do campo para os domínios das ciências cognitivas e das ciências sociais, 
como tem ocorrido nos últimos anos. Nessa conjuntura, o artigo ora apresentado objetiva contribuir para o debate no campo, defendendo a referenciação como ato político e salientando seu papel na construção dos objetos de discurso que compõem a realidade social.

Investigaremos, portanto, a construção identitária do movimento Occupy Wall Street (doravante OWS) em dois textos publicados no início do movimento, na fase das ocupações, a partir das expressões referenciais mobilizadas nos textos, as quais compõem uma cadeia que estabelece uma relação de equivalência entre referentes diversos, a partir de um ponto articulador comum - ponto nodal. Para tanto, lançamos mão da teoria do discurso proposta por Ernesto Laclau \& Chantal Mouffe ([1985] 2015; 1990; LACLAU, 1990; 2011; 2013) e da referenciação, na perspectiva de autores como Mondada \& Dubois (2003), Marcuschi (2007; 2008) e Cavalcante (2011), nos apropriando, sobretudo, da categoria sociodiscursiva de cadeia de equivalência e das categorias textual-discursivas de introdução referencial, anáfora e dêixis, que constituem o conjunto dos processos referenciais.

Cabe esclarecer que o movimento OWS iniciou-se em Wall Street em 2011, como o primeiro de uma série de movimentos de ocupação ${ }^{1}$, influenciado pela Primavera Árabe e os Indignados Espanhóis. À época, milhares de pessoas - negros, mulheres, idosos, desempregados, etc. - ocuparam as ruas de Manhattan, Nova Iorque, apresentando-se como "os 99\%", para manifestar sua indignação com a "corrupção e a ganância do 1\%", que, em 2007, controlava 23,5\% da renda americana (CASTELLS, 2013, p. 121); e com as medidas de austeridade empreendidas por um Estado americano condescendente com os interesses do capital financeiro, mediante a crise econômica que assolava o mundo inteiro desde 2008. A influência do OWS estendeu-se por milhares de cidades pelo mundo, e vários protestos que usavam da tática da ocupação - portanto, inclusive, a denominação Occupy, ou Ocupa, como no Brasil ${ }^{2}$ - ganharam força.

Iniciaremos, portanto, com uma discussão do referencial teórico que norteia o estudo por este artigo apresentado, para chegar às considerações metodológicas e à análise, a qual nos levou a conclusões tanto em relação à construção identitária do

\footnotetext{
${ }^{1}$ A estratégia de ocupação dos espaços públicos não é recente na prática dos movimentos sociais. O que estou querendo aqui afirmar é que o movimento de ocupação conhecido como Occupy Movement teve sua primeira manifestação em Wall Street.

${ }^{2}$ A saber, o Ocupa Sampa e o Ocupa Rio.
} 
movimento, que, como veremos, tende a funcionar como o significante de uma indeterminação - ou, nos dizeres de Laclau, um significante vazio - quanto também no que diz respeito aos processos referenciais em sua articulação com a teoria do discurso.

\section{O discurso como co-construtor da realidade social}

Cremos que, para pensar a referenciação como ato político inserido em relações de poder, indo além do seu caráter de negociação dos sentidos, é necessário ampliar a concepção de discurso que domina muitos dos estudos linguísticos, atribuindo-lhe, além de seu estatuto ôntico, como linguagem em uso, um estatuto ontológico. Para tanto, cabe esclarecer a noção de discurso da qual nos apropriamos, e como ele está envolvido com a sociedade e sua dimensão inerradicável - a saber, o político ${ }^{3}$.

Ernesto Laclau e Chantal Mouffe ([1985] 2015; 1990), ao lançar as bases da teoria do discurso (doravante TD), indicarão que este é "coextensivo ao ser dos objetos" (LACLAU \& MOUFFE, 1990 - itálico dos autores). Dessa forma, um objeto esférico ${ }^{4}$, por exemplo, é somente uma bola de futebol "na medida em que estabelece um sistema de relações com outros objetos, e essas relações não são dadas pela simples materialidade referencial dos objetos, mas são antes socialmente construídas" (LACLAU \& MOUFFE, 1990, p. 105).

Laclau, à semelhança de diversas perspectivas de correntes linguísticas, considera o discurso como uma prática em que a significação é produzida, uma forma de ser e agir no mundo, aduzindo que sua condição ontológica é a política, no sentido de que ele é algo que se relaciona intimamente com a produção de um sistema de significação que envolve fatos físicos, biológicos, etc. - sua preocupação é mostrar "o lugar que a questão do sentido precisa ter numa reflexão sobre a ação social” (BURITY, 2014, p. 61). Para compreendermos isso com maior clareza, primeiramente, é necessário que tenhamos um entendimento do que seja uma prática articulatória, que funciona como o modo de construção dessa significação.

\footnotetext{
${ }^{3}$ Chantal Mouffe (2005) define o político como a "dimensão do antagonismo inerente às relações humanas [porque permeadas de uma pluralidade de valores conflitantes], um antagonismo que pode tomar muitas formas e emergir em diferentes tipos de relações sociais" (Ib., p.174). Esse conceito difere do conceito de política, à medida que esta seria o conjunto de regras, práticas e discursos que procuram estabelecer a ordem e organizar a existência humana afetada pelo político.

${ }^{4} \mathrm{E}$ o próprio fato de considerar o objeto como um objeto esférico é fruto de uma categorização operada no interior de um sistema de relações (discurso).
} 
Por esta, Laclau \& Mouffe (2001, p.105) entendem "toda prática que estabelece uma relação tal entre elementos, que a identidade destes termina por modificar-se como resultado dessa prática"5. Os elementos correspondem a toda diferença que será articulada, e, quando isso ocorre, tornam-se momentos (identidades) em relação à prática que os articulou. $\mathrm{O}$ ponto de amarração articulador dessas diferenças, responsável pela fixidez relativa dos momentos, é chamado ponto nodal. O resultado disso é o que se compreende aqui por discurso, em uma concepção mais ampla, que vai além das operações de fala e escrita no sentido estrito dos termos, e que apresenta um caráter material $^{6}$. Toda prática social é, para os autores, uma prática articulatória, pois consiste em estabelecer a fixação do sentido através dos pontos nodais. Essa fixação, apesar de poder ter certa estabilidade, nunca chega a ser total, e sempre se depara com sua impossibilidade resultante também do caráter aberto do social e da pluralidade de discursos que o constitui - ou pelo excesso de sentido que subverte todo discurso, e que se deve ao que Laclau (1990) denomina deslocamento estrutural ${ }^{7}$.

Desse modo é que o discurso é uma totalidade significante (signifying totality) estruturada construída por um conjunto sistemático de relações de sobredeterminação, em que estão incluídas ações linguísticas e não linguísticas ${ }^{8}$. Não podemos esquecer, sob pena de incorrermos em um abstracionismo ou mentalismo redutor, que as articulações que produzem discurso se dão no decorrer das práticas sociais: na medida em que a vida é vivida, é que os discursos se (re)constituem, já fazendo parte de uma arena de tensão, do campo da discursividade, em que têm de conviver com outros discursos muitas vezes antagônicos, momento em que se inserem na batalha por um lugar privilegiado na sociedade, ou seja, o lugar da hegemonia.

\footnotetext{
${ }^{5}$ No original: "[...] any practice establishing a relation among elements such that their identity is modified as a result of the articulatory practice".

${ }^{6}$ Considera-se, ainda, uma concepção mais particular de discurso, como uma espécie de ativação de recursos linguísticos, no sentido estrito do termo, embora essa não seja a noção mais explorada por Laclau, visto que ele toma o discurso como categoria teórica. Ademais, os discursos, como sistemas significativos, também estão atrelados às diversas esferas e instituições da sociedade - assim, temos discurso religioso, discurso econômico, discurso educacional, etc.

${ }^{7} \mathrm{O}$ conceito de deslocamento passa por uma compreensão do conceito de real em psicanálise. Grosso modo, podemos considerar o deslocamento como uma desestabilização que resulta desse real, dessa contingência radical, que é sempre externa à ordem estabelecida, apresentando o limite do sentido, a falha que põe uma estrutura em xeque.

${ }^{8}$ Não confundir a distinção linguístico vs. não linguístico com significativo vs. não significativo, visto que toda ação, inclusive não linguística (como chutar uma bola), tem um significado que a ela é atribuído no interior de um discurso (chutar uma bola em um jogo de futebol assume um significado diferente de chutar uma bola na rua para devolvê-la a alguém, por exemplo).
} 
Dito isso, como podemos pensar, portanto, a referenciação a partir dessa noção de discurso? Obviamente, não podemos mais falar em uma ideia de representação em que o significante, "permanecendo como um meio de expressão neutro e transparente", (CARDOSO, 2003, p.119) pressuponha um Significado, que, por sua vez, se refira diretamente a algo no mundo. É por sabermos que o discurso ocupa um lugar primordial na construção do mundo e das experiências, e que, conforme afirma Maturana (2001, p. 37), "a realidade é sempre um argumento explicativo", no sentido de que é a linguagem que dá sentido ao mundo e que pode haver tantas realidades quantos forem os discursos produzidos por aqueles que se põem a observá-la, que a referência deve ser vista a partir de uma perspectiva construtivista, como um processo - daí o nome referenciação (MONDADA \& DUBOIS, 2003) -, levando sempre em conta aqueles que a constroem.

Assim, além de o referente poder ser pensado como uma fabricação sociocognitivo-discursiva, gerado intersubjetivamente na prática social (KOCH, 2015), defendemos que ele também pode (e deve) ser pensado como aquele que constituirá o objeto de discurso pelo qual se luta, cuja significação se insere no processo de disputa pela hegemonia na constituição de uma ordem, podendo, então, influenciar de modo mais efetivo "as construções sociais da realidade, as práticas sociais e, por conseguinte, a (trans)formação das estruturas societais" (VAN DIJK, 2012, p.49). Isso faz com que a referenciação, além de pressupor uma negociação intersubjetiva, também pressuponha um conflito, um processo de luta para tornar hegemônicos os significados dos referentes. Se colocarmos tudo isso em termos laclaunianos, podemos dizer que o referente corresponde ao elemento que vai sendo transformado em momento ao longo do texto, e a referenciação também como o processo em que ocorre a transição de um a outro, chegando a um final provisório do conflito/da negociação e constituindo um ponto de estabilização relativa e temporariamente hegemonizado - o objeto de discurso.

\section{Antagonismo, cadeias de equivalência e processos de referenciação na construção de identidades}

Já afirmamos que identidades nada têm a ver com permanência ou essência: elas devem ser compreendidas como objetos de discurso, como o resultado provisório de uma prática articulatória, a qual mobiliza certos elementos/referentes. O conceito de 
identidade coletiva, neste artigo, guarda íntima relação com o conceito de antagonismo, sobretudo se pensamos em nosso objeto, o OWS, ou os 99\%, que se constitui a partir de uma relação antagônica com o $1 \%$.

O antagonismo pode ser visto a partir de dois níveis. Ao nível ontológico, apresenta-se como o que Zizek (1990) denomina antagonismo primário, não contemplado pela teoria laclauniana, apesar da alusão ao conceito, que Laclau faz em alguns de seus trabalhos. Esse antagonismo ocorre entre o real (a contingência radical, a dimensão que escapa à simbolização), do qual o deslocamento é um momento, e o simbólico (a tentativa de construir a ordem social, que ocorre por meio de articulações discursivas). Destarte, o real impossibilita a sutura do simbólico, que tenta domesticá-lo (construir uma ordem suturada, com leis necessárias de desenvolvimento previsíveis e posições de sujeito definidas uma vez por todas), mas que é incapaz de realizar plenamente seu sentido (o real, como terreno de uma contingência radical, sempre retorna) - o que quer dizer que a barreira saussuriana entre significante e significado nunca poderá ser transposta, pois que aquele nunca chegará a unir-se inteiramente, plenamente, a este.

No nível da realidade, ele caracteriza os diversos conflitos entre posições de sujeito, emergindo a partir da percepção de uma ameaça, que, como afirma Mendonça (2012), dá início à produção de um processo articulatório de elementos e, consequentemente, um discurso. As identidades antagônicas e seu discurso são formados por práticas que articulam elementos em seu interior, transformando-os em momentos para a formação de um nós em contraposição a um eles. Esses elementos articulados tendem a formar uma cadeia, de modo a estabelecerem entre si uma relação de equivalência que nada tem de apriorística. Assim é que um elemento é eleito como o ponto em comum entre todos os outros que compõem a cadeia, mas isso só ocorre porque há um discurso que os constitui, significa-os como tal, hegemonizando um elemento específico (o ponto nodal em comum) e colocando todos os outros numa relação de equivalência, a qual não iria além "de um vago sentimento de solidariedade, caso não se cristalizassem numa certa identidade discursiva" (LACLAU, 2013, p. 150). Esse momento de cristalização é o que Laclau afirma ser o momento da constituição do "povo" enquanto plebs (plebe) que almeja ser um populus (povo). Nesse sentido, o OWS seria um movimento em que, ao menos em sua primeira fase, assumiu uma lógica 
populista, não no sentido tradicional dessa categoria, mas enquanto lógica política, ou seja, uma lógica que, independente de quaisquer conteúdos sociais ou ideológicos, procede de demandas sociais e é inerente a qualquer processo de mudança; uma lógica que ocorre através da articulação variável entre equivalência e diferença em que uma dessas diferenças assume a ideia de uma plenitude ausente e emerge em uma relação antagônica ${ }^{9}$.

A extensão de elementos dentro de uma cadeia de equivalência pode ir perdendo sua ligação a um significado particular, instaurando-se como um significante vazio (LACLAU, 2011; 2013), ou seja, como o significante que cancela as diferenças e, assim, promove certa indeterminação. As diferenças não são eliminadas, mas dissolvidas em cadeias equivalenciais ${ }^{10}$. Na luta hegemônica, um grupo que se proponha a fornecer significados para estabelecer determinada ordem precisa promover uma identificação com um conjunto amplo de valores, grupos e demandas sociais. Faz-se necessário, assim, construir uma extensa cadeia de equivalência que componha uma identidade política com características universais para o movimento. Um universal forjado por um particular (os destituídos de poder econômico ou de poder de decisão, no caso do OWS), o que se torna possível pela presença de significantes vazios, configurando uma plenitude ausente, posto que existe como uma promessa, um horizonte para determinada ação política.

Ora, estas equivalências se constroem por através dos processos referenciais, à medida que as identidades, "sendo uma superfície de inscrição, não expressam passivamente o que está inscrito na cadeia [de equivalência], mas na verdade constituem o que eles expressam através do próprio processo de expressão" (LACLAU, 2013, p.158 - itálicos do autor), o que quer dizer que não se trata de expressar, como em uma revelação, aquilo que se é e o que se tem em comum com outros, mas de construir isso no curso da interação. Sendo assim, a análise dos processos textual-discursivos de referenciação mobilizados na construção do objeto de discurso em questão, os quais

\footnotetext{
${ }^{9}$ É por considerar o caráter movente que a articulação pressupõe que, quando falamos em analisar a identidade política do OWS em dado momento, o fazemos no sentido delimitar um recorte, enxergando o grupo sob uma perspectiva em um determinado período espaço-temporal, visto que depois disso (e até mesmo durante) várias (re)articulações ocorreram, produzindo outras recategorizações.

${ }^{10}$ Devemos atinar aqui para o fato de que uma total equivalência entre as diferenças, sonho do projeto totalitário, é algo impossível, dada a tensão inerente à pluralidade do social com seus valores e interesses por vezes antagônicos.
} 
estabelecem uma cadeia referencial (MARCUSCHI, 2008), ajuda-nos a compreender de modo mais evidente a implicação mútua entre linguagem e sociedade.

Assim, as pistas expressas no, e incorporadas ao, co(n)texto nos ajudam a desenhar em nossa mente, de um ou de outro modo, determinado objeto de discurso, a partir da articulação que os elementos estabelecem no texto (CAVALCANTE, 2011). Dessa maneira, confirmações e reformulações se sobrepõem, culminando numa cadeia de elementos articulados que se equivalem e constroem provisoriamente o objeto de discurso. A equivalência aqui apontada não corresponde a uma equivalência de natureza meramente semântica, mas a uma equivalência entre elementos (entenda-se elementos como os referentes que constituem valores, crenças, características, instituições e posições de sujeito) que é criada numa performance. A equivalência se estabelece por estarem esses elementos, de algum modo, conectados a um referente em comum.

Atualmente, consoante Cavalcante (2011), é possível dividir duas vertentes nos estudos em referenciação quanto aos modos de abordar os objetos de discurso em textos, a despeito de ambas as vertentes considerarem na análise a conjugação de pistas fornecidas pelo cotexto com dados do entorno situacional e sociocultural mais amplo. A primeira, mais tradicional, prioriza a manifestação cotextual das expressões referenciais; nessa perspectiva (a dos referidos pela autora como "processos atrelados à menção"), os processos referenciais dividem-se em introdução referencial e anáforas, podendo estas serem diretas (correferenciais) ou indiretas (não correferencais), incluindo-se, ainda, as anáforas encapsuladoras. Há também o fenômeno da dêixis, que se define pela capacidade de criar um vínculo entre o cotexto e a situação enunciativa. $\mathrm{O}$ segundo modo, que não deixa de ter proximidade com o primeiro, está mais focado na dimensão sociocognitiva do fenômeno, sem se prender à manifestação das expressões referenciais no cotexto como critério definidor de distinções.

Embora, no desenvolvimento das pesquisas em referenciação, várias tentativas taxonômicas tenham surgido, objetivando dar conta da análise da materialidade textual, o que se observa é que elas falham na tentativa de cerrar o fenômeno em categorias analíticas totalizantes. Isso se deve não a uma insuficiência teórico-metodológica, mas à própria complexidade do processo de construção do sentido, que não permite ser encerrado em classificações herméticas. Por ter caráter não linear e por mobilizar uma série de aspectos de natureza não apenas estritamente linguística, mas também 
sociocognitiva, a referenciação escapa a qualquer tentativa de fechamento e aplicação de categorias previamente estipuladas, o que não significa que não podemos formular categorias analíticas para pensar esses processos. A questão está muito mais ligada ao modo como encaramos o texto na análise, e como consideramos a atuação de fenômenos como, por exemplo, anáforas e dêixis: de modo mais aberto, considerando o comportamento e função das expressões em uso para a construção do sentido, ou de modo mais hermético, limitando-nos à análise de algumas construções textuais.

Neste trabalho, não concentraremos nossa atenção analítica apenas nas tradicionais expressões referenciais manifestas no cotexto, embora elas sejam indiscutivelmente importantes para a elaboração dos objetos de discurso, mas levamos em consideração os processos referenciais também a partir de outros tipos de manifestações (con)textuais para traçar possibilidades de leitura.

\section{Compondo equivalências: analisando a construção identitária do Occupy Wall Street}

\subsection{Considerações Metodológicas}

Os textos analisados consistem em postagens de blog publicadas em um dos sites oficiais do OWS ${ }^{11}$, à época do início do movimento, e recebem os títulos "Pais trazem crianças ao \#ows esta noite" e "Vitória do \#OWS: o povo tem prevalecido, preparem-se para o dia global de ação"12. Eles são parte de um conjunto de textos que circularam nos primeiros meses de emergência do movimento e, portanto, foram analisados levando em consideração a rede de textos em que se inserem. Em decorrência do gênero textual que ora escrevemos, apresentamos aqui apenas alguns trechos desses textos para ilustrar a análise.

Inicialmente, por se tratar de textos escritos em língua inglesa, fizemos uma tradução para facilitar a análise. Justificamos o gesto considerando que mesmo em uma análise do texto-fonte propriamente dito, já estaríamos, ao lê-lo, de certa forma interpretando a partir da língua materna. Assim, recorremos a algumas técnicas

\footnotetext{
${ }_{11}^{11}$ A saber, http://occupywallst.org/article/parents-bring-children-ows-tonight/.

12 No original, respectivamente: "Parents bring Children to \#ows tonight" e "\#OWS VICTORY: The people have prevailed, gear up for global day of action".
} 
(VINAY \& DARBELNET apud AUBERT, 1998), relacionadas a uma modalidade direta de tradução - a transposição -, e a uma modalidade indireta - a modulação, em que se opera um "deslocamento na estrutura semântica de superfície"13. Utilizamos, ainda, como instrumentos auxiliares os dicionários online Word Reference e Linguee, e o Urban dictionary, que não consiste em um dicionário de tradução entre línguas, mas de gírias e expressões idiomáticas do inglês. Além disso, não hesitamos em buscar a colaboração de alguns colegas profissionais que já trabalham com tradução, para esclarecer um ou outro termo que impôs dificuldades à análise, submetendo toda a tradução a uma revisão.

Em seguida, procedemos à análise dos processos referenciais, a partir tanto das expressões referenciais explicitadas no cotexto, quanto do que nos foi possível inferir e resgatar de uma memória discursiva, com base nas âncoras manifestas, para construir possibilidades de sentido à respeito da identidade política do movimento, que o coloca em relação a seu outro.

O texto que analisamos a seguir pode ser caracterizado como pertencendo ao gênero blog e visa a fornecer informações praticamente em tempo real acerca das ações do movimento e dos últimos acontecimentos nas ocupações. Longe de sustentar uma visão ingênua, assumimos o posicionamento de que, pelas próprias escolhas feitas pelo produtor do texto, mesmo as notícias divulgadas no site, as informações fornecidas nos textos, as quais têm, à primeira vista, apenas a pretensão de informar, servem a um projeto de dizer, sendo, portanto, de caráter extremamente argumentativo, contribuindo para construir acerca do fato uma realidade que produza efeitos de verdade.

\subsection{Análise do corpus}

O primeiro texto se inicia com o título "Pais trazem crianças ao \#ows esta noite", em que são introduzidos três referentes, por meio das expressões referenciais [Pais], [crianças] e [ows], sendo este último utilizado sob a forma em que aparece usualmente nas redes sociais, acompanhada do uso da hashtag ${ }^{14}$, o que reforça o caráter em rede do

\footnotetext{
${ }^{13}$ Em alguns casos, quando o termo/expressão apresentado/a for bem específico/a da língua do textofonte, este/esta será explicitado/a na análise aqui explanada.

14 A hashtag abriga um item lexical ou expressão que funciona como articuladora de determinados conteúdos compartilhados nas redes sociais. Elas se transformam em uma espécie de hiperlink que direciona para todos os conteúdos em que aparece, ou seja, ao colocar na rede social Twitter, ou
} 
movimento. Esses três referentes vão se associando no texto, de modo a favorecer determinada construção da imagem do OWS, como no trecho

Famílias estão se engajando no movimento para recuperar o nosso futuro de Wall Street hoje à noite, ao aderirem a um acampamento receptível às crianças, na Liberty Square. A presença de crianças e jovens na ocupação destaca a ameaça que a ganância de Wall Street representa para as gerações futuras. Os pais estão trazendo seus filhos e filhas para o Occupy Wall Street para educá-los sobre o nosso sistema econômico quebrado e as alternativas que poderiam ajudar a salvar o planeta e proporcionar um futuro para $a$ próxima geração.

Podemos considerar a expressão [Famílias] como um anafórico indireto de tipo conceitual, que envolve o resgate de um esquema cognitivo preparado pelas expressões [Pais] e [crianças], ao qual depois é acrescentado um outro referente: [jovens]. Ademais, estes se articulam à cadeia do [ows] - retomado por meio da expressão anafórica direta [o movimento] - através do verbo engajar. Essa articulação, realizada através de um verbo, justifica-se pelo fato de que, ao afirmar-se um engajamento, passa-se a ver o referente como parte de um outro; isso ocorre não por alguma relação que já esteja dada de antemão, em algum sistema abstrato, mas por um entrecruzamento que é construído no discurso, como já afirmamos em relação à construção da cadeia de equivalência. Esses referentes, entrelaçados, unem-se na forma pronominal anafórica/dêitica (porque aponta para o enunciador) [nosso] - em "nosso futuro" -, a qual faz referência tanto a [Famílias] quanto a [ows], ratificando o amálgama iniciado já com o verbo engajar e posteriormente reforçado pelo verbo aderir (em "ao aderirem...").

Um "nós" vai se estabelecendo a partir da contraposição a um "eles", instaurado no texto pela expressão [Wall Street], que remete não ao espaço geográfico, mas a uma entidade considerada o coração do capitalismo, refere-se a tudo o que essa entidade representa - tal relação pode ser estabelecida e confirmada ao longo do texto, sobretudo se o leitor tiver um conhecimento prévio mínimo a respeito desse objeto de discurso. A esse referente é associado o sentimento de "ganância" - e, consequentemente, a ideia de ameaça -, à qual tanto o movimento quanto as famílias se opõem. A missão de "salvação" é atribuída a estes referentes, dos quais depende o futuro d[as próximas

Instagram, por exemplo, a hashtag \#OWS no campo de busca, logo aparecem as publicações que a utilizaram. Por trás das hashtags, podemos dizer, há um trabalho de ostensão - uma dêixis - "que sugere uma ligação possível mediante uma espécie de relevância mostrada" (MARCUSHI, 2007, p. 160 - itálico do autor -, ao falar a respeito do link do hipertexto, que podemos assemelhar à hashtag). 
gerações], expressão indicadora de anáfora indireta que recupera [crianças], [jovens] e, por conseguinte, [seus filhos e filhas].

O movimento é ainda referido por meio de anáfora indireta em [um acampamento receptível às crianças], caracterização importante se atentarmos para o fato de que, em geral - e provavelmente à época em que os acampamentos estavam no seu auge -, a ideia que se tem de ocupações e protestos é estranha a um ambiente que seja receptível ao público infantil. Em razão disso, é possível afirmar que mais do que uma recategorização do próprio referente [ows] é empreendida: o que podemos dizer que ocorre é uma tentativa de recategorização do modelo que se tem de ocupação ou acampamento de protesto, a partir do modelo de ocupação do próprio movimento.

Em sequência, temos:

\begin{abstract}
Quem deve vir? Famílias dispostas a se integrar ao bate-papo dos 99\% sobre os planos de Bloomberg de remover manifestantes do Zuccotti Park/Liberty Square, contra a sua vontade para a limpeza, forçando pais a cancelarem nossa sexta-feira de vigília em família, mas isso não será silenciado.

Convidamos pais para vir à Wall Street, 60, sexta à noite às 20h, com suas crianças para compartilhar a mensagem de que famílias são a parte central da discussão do Occupy Wall Street. Convidamos você a participar $\mathrm{d} a$ assembleia e expor suas questões. Não há nada menos atraente para $a$ administração de Bloomberg e seus associados do que ver os pais e seus filhos tão engajados no Occupy Wall Street a ponto de passarem a noite em um parque público com suas crianças.
\end{abstract}

A expressão anafórica direta [os 99\%] retoma [ows] de forma a fazer com que o referente da expressão [Famílias] se diferencie deste, num movimento de diferenciação - e aqui percebemos o movimento de construção de equivalência na diferença: esta não é eliminada, mas integrada ao todo. Há ainda uma delimitação respeitante a [Famílias], que o recategoriza, visto que as famílias convidadas pelo enunciador são [Famílias dispostas a se integrar ao bate-papo] dos 99\%, ou seja, há a condição de se submeter ao que está sendo proposto como debate (sem a obrigação de consentir com o proposto), mas sem que se diga como isso será gerenciado. A dimensão conflitiva, de tensão, parece ser elidida do discurso, possivelmente em razão de se tentar nele construir uma equivalência, garantir a identificação e conquistar a adesão.

O referente introduzido pela expressão [Bloomberg] aparece sob a forma do dado, provavelmente por acreditar-se que o acesso a esse referente seja fácil, 
pressupondo certo conhecimento sociopolítico do leitor ${ }^{15}$, a respeito da realidade norteamericana. Esse referente pode ser (re)categorizado como alguém que age forçosamente - no intuito de remover "contra a sua vontade" - contra o referente de [manifestantes], anáfora direta de [ows], colocando-se [Bloomberg] em posição contrária aos 99\%.

Há uma recategorização, via anáfora indireta, do referente de [a ocupação] em "nossa sexta-feira de vigília em família”, em que esse nossa, um dêitico anafórico, amalgama o enunciador, que se apresenta como parte de [ows] e o referente [Famílias]. A "ocupação", o "debate", o "acampamento", o "protesto" são transformados em uma [vigília em família], com toda a carga afetiva que essa expressão pode fazer emergir, criando uma atmosfera que resgata da memória de muitos a ideia de harmonia, solidariedade e união.

O enunciador que enuncia em nome do movimento utiliza um verbo de modo a propor a força ilocutória de um convite, em oposição a uma convocação ou a uma conclamação, que talvez fosse o mais esperado para um modelo mais hegemônico de acampamento de protesto. A escolha dessa forma de interação ajuda a reforçar a atmosfera pacífica e "familiar" proposta ao longo de todo o texto. "Wall Street" é agora diferente do referente introduzido no início do texto: trata-se do local da ocupação, o qual acompanham data e hora.

O referente [Famílias] é recuperado pela expressão predicativa, que consideramos constituir uma anáfora direta, [a parte central da discussão do Occupy Wall Street] - aqui, a família também é o centro, e ela é chamada a participar d[a assembleia] (remissão anafórica indireta em relação a [ows]) e expor questões, participando do debate. O OWS é mais uma vez construído como aquele que permite essa participação no debate, e esse engajamento n[o Occupy Wall Street], que põe [os pais e seus filhos] (final do $3^{\circ}$ parágrafo) em equivalência com este, é visto como algo pouco atraente (less attractive) aos olhos d[a administração Bloomberg] e [seus associados], que constituem o lado de lá da fronteira.

\footnotetext{
${ }^{15}$ Aos leitores deste artigo que não tiveram fácil acesso a esse referente na sua memória, deixamos a informação de que "Bloomberg" faz referência ao prefeito de Nova Iorque à época, Michael Bloomberg, fundador de uma das maiores empresas de comunicação do mundo, cujo mandato, um dos maiores da história norte-americana, durou entre os anos de 2002 e 2013.
} 
Ao longo do texto, percebemos que o [nós] que fala em nome do movimento se coloca na posição de quem "procura construir" alianças com [outros grupos de famílias que apoiam o Occupy Wall Street], buscando conquistar a adesão de outros grupos e expandir sua cadeia equivalencial; o desfecho apresenta dois pronomes que reiteram a articulação entre [ows] e [famílias], [crianças], [jovens], [o radical], etc.: [nós] e [nossos (filhos)], incluindo também o enunciador.

Em se tratando do segundo texto, cujo título é "Vitória do \#OWS: o povo tem prevalecido, preparem-se para o dia global de ação", o movimento é introduzido no universo cotextual pela expresão [\#OWS] - o que pode ser também considerado uma anáfora correferencial de [\#ows], introduzido no título do texto anterior. Há, ainda, a identificação desse mesmo referente com o referente [o povo], pela alusão à "vitória" do movimento como indicação de que [o povo] "tem prevalecido".

Um trecho representativo desse texto é o que segue.

O poder do povo triunfa sobre a proposta de Wall Street para encerrar os protestos, o prefeito Bloomberg e a Brookfield Inc. desistiram do despejo enquanto o mundo se prepara para o dia da ação no sábado, 15 de outubro, em mais de 950 cidades em 82 países. Estamos ganhando!

Nova York, NY - Mais de 3.000 pessoas se reuniram na Liberty Square nas primeiras horas antes do amanhecer nesta manhã, para defender a ocupação pacífica perto de Wall Street. A multidão aplaudiu a notícia de que a empresa imobiliária multinacional Brookfield Properties irá adiar a sua chamada "limpeza" do parque, e que o prefeito Bloomberg disse ao departamento de polícia de Nova York que retiraria as ordens para a remoção dos manifestantes. [...]

O início do texto apresenta um breve resumo do acontecimento relatado. A relação antagônica [o povo] vs. [Wall Street] é reiterada, à medida que [o poder] daquele "triunfa" - numa metáfora de guerra, de batalha ou disputa - sobre [a proposta] deste, fazendo-os "desistir" da ação referida pela expressão [o despejo], nominalização de um fazer articulado à cadeia de [Wall Street], enquanto o referente [os protestos] pode ser articulado à cadeia do [\#OWS].

Os referentes introduzidos no cotexto pelas expressões [o prefeito Bloomberg] e [a Brookfield Inc.] são aqui considerados também anáforas indiretas de [Wall Street], representado pela expressão [1\%], numa relação parte-todo baseada em inferências que se ancoram no modelo de mundo textual e em conhecimentos de mundo: o prefeito e a empresa representam Wall Street e seus interesses, ou seja, os interesses do capital, cuja 
ação é despejar pessoas de suas residências, colocando-se do lado oposto do povo. Já o referente [o mundo] pode ser articulado à cadeia do [\#OWS], também como uma AI baseada no mesmo tipo de inferência, mas não necessariamente pela mesma relação parte-todo em sua totalidade, visto que $\mathrm{n}$ [o mundo] estão inclusos tanto os que se preparam ativamente, engajados no grupo, como os que se preparam passivamente, como espectadores, para aquilo que referenciam como [o dia global da ação] - retomado via anáfora direta por [o dia da ação].

O referente da elipse em "Estamos ganhando" - ou seja, do [nós] - apresenta uma certa ambiguidade, uma vez que pode se referir apenas ao referente [\#OWS], em uma anáfora direta, ou pode articular mais uma vez os referentes [\#OWS] e [o povo] à mesma cadeia, como uma AI.

Há também um referente introduzido pela expressão [3.000 pessoas], que é recuperada pela expressão anafórica indireta [A multidão], sendo que esta vai se recategorizando ao longo do texto, e, quando chegamos ao final, vemos que se trata de um amálgama entre os referentes de [3.000 pessoas] e [os manifestantes], incluindo-se também outros referentes que vão constituindo a cadeia, o que podemos ilustrar neste trecho, o qual constitui o quinto parágrafo do texto:

\footnotetext{
Às 6h desta manhã, mais de 3.000 nova-iorquinos, sindicatos, estudantes e outros se juntaram aos ocupantes na praça para enviar uma mensagem clara para o $1 \%$ que quer silenciar esta reunião pacífica dos $99 \%$. Doações foram vertidas para os manifestantes da Itália, Inglaterra, México e muitos outros países, por pessoas comuns, na esperança de ajudar o movimento a crescer.
}

Nele, o referente de [A multidão] é desmembrado nos referentes de [mais de 3.000 nova-iorquinos], [sindicatos], [estudantes], [outros] e [os ocupantes], todos considerados aqui como constituindo anáforas indiretas, e estão unidos na posição de agentes, enviando [uma mensagem clara] ao seu outro, ou seja, o referente de [o 1\%], o qual quer "silenciar" aquilo que é construído como [esta reunião pacífica dos 99\%], que reforça a atribuição de um caráter pacífico ao movimento e faz o referente evoluir. Além disso, a expressão [os 99\%] reforça o agrupamento dos referentes de [3.000 novaiorquinos], [sindicatos], [estudantes], etc.

A anáfora direta expressa em [o movimento], no trecho "ajudar o movimento a crescer", inclui os referentes de [os manifestantes da Itália], [(os manifestantes da) Inglaterra], [(os manifestantes do) México] e [muitos outros países], expandindo a 
cadeia referencial/equivalencial do [\#OWS], ao mostrar que também o referente de [pessoas comuns] se integram ao movimento por prestarem solidariedade através de "Doações".

Aqui já somos capazes de tirar algumas conclusões com relação ao que vimos a respeito dos processos referenciais em articulação à teoria do discurso na análise. Em primeiro lugar, temos que o grande processo responsável pela construção de uma cadeia equivalencial entre diferentes elementos é o da referência anafórica indireta, especialmente os encapsulamentos. Por meio dele, relações do tipo parte-todo podem ser criadas sem que necessariamente já pertençam a modelos mentais prévia e relativamente estabelecidos, e referentes podem ser reunidos sob uma mesma expressão, construindo, assim, equivalências entre eles que ajudam, a partir mesmo dessa relação, a construir suas identidades. Ademais, as recategorizações, conforme já apresentado em diversas pesquisas na área, não são operadas exclusivamente por anafóricos diretos. Podemos considerar também que algumas anáforas diretas exigem maior trabalho inferencial que outras, mas, consoante também já fora apontado por diversos pesquisadores, todas pressupõem algum tipo de inferência. Aqui pudemos ver isso, em alguns momentos, com maior clareza.

Em segundo lugar, quando se trata de autorreferência, como é o caso dos textos em que o enunciador fala em primeira pessoa para construir a si mesmo enquanto objeto de discurso, as expressões predicativas, inclusive as que instauram novos referentes, e os verbos, mesmo não sendo considerados expressões referenciais, são importantíssimos para a construção dos referentes. Os verbos, de modo especial, indicam que processos estão geralmente sendo associados a cada um deles, e isso nos ajuda a compreender como o enunciador o caracteriza a partir de suas atitudes. No caso do movimento OWS, pudemos ver a quantidade e a qualidade dos processos materiais e mentais a ele relacionados, sobretudo expandindo o corpus, o que nos pode sugerir um movimento sempre em ação, que envolve as pessoas levando-as a refletir e agir em favor de uma mudança profunda na sociedade.

Vamos percebendo, ao longo da análise, uma relação de implicação mútua entre a cadeia referencial e a equivalencial, sendo impossível segregá-los na análise, o que atesta a inviabilidade de separar o textual (cadeia referencial) do discursivo (cadeia de equivalência). 
A voz que fala em nome do movimento constrói-se, ainda, como um grupo em que predomina a solidariedade e a cooperação entre os membros, uma relação harmônica e familiar, que preza por cultivar valores como justiça, igualdade, transparência, cooperação, etc. ${ }^{16}$, através de seu fazer. Esses referentes constituem valores que são postos como ausentes numa sociedade controlada pelos interesses do capital, o que pode nos levar à conclusão de que qualquer demanda que busque uma conjunção com eles encontra-se em oposição àquele que os torna ausentes, ou seja, se opõem ao mesmo regime opressor, condição segundo a qual uma comunidade de equivalência, referida como uma totalidade, pode ser estabelecida (LACLAU, 2011, p. 208).

É daí que surge o perigo, exemplificado na crítica que o pesquisador norteamericano Jason Hickel (2012) fez ao Occupy. Ele vê na afirmação da igualdade, na ideia de solidariedade, na busca do consenso e em outras posturas e significações construídas pelo Occupy, sobretudo na postulação de uma democracia participativa baseada no consenso - que, em parte, vimos nos textos analisados -, pressupostos e subjetividades que organizam o neoliberalismo, discurso ao qual o próprio movimento se opõe. Ora, se essa ideologia atravessa o discurso do OWS, há nele uma grande contradição, um ponto de tensão. Obviamente, são dois discursos diferentes, os elementos são articulados de modos diferentes e qualquer generalização, sobretudo neste artigo - em que operamos sobre um recorte -, constitui enorme perigo; contudo, podemos afirmar, sem medo, que ambos mobilizam certos referentes cujas significações podem cruzar-se e confundir-se, possibilitando apropriações tidas como perigosas para a formação da identidade contra-hegemônica. O Occupy Wall Street percebeu que o argumento da luta de classes não parece estar mais à altura de construir uma narrativa convincente, e elidiu a ideia de classe de sua construção, renomeando as identidades dos polos antagônicos que figuram na luta como os "99\%" contra o " $1 \%$ "; no entanto, muitos podem à época não ter ponderado a respeito do risco que a mobilização de certos referentes poderia trazer - e trouxe -, dado seu momento flutuante que constitui todo e qualquer significante.

\footnotetext{
${ }^{16}$ Isso é mais perceptível quando ampliamos o corpus e deparamos com outros textos do movimento, o que pode ser visto em Cavalcante, T., 2016.
} 


\section{CONCLUSÃO}

O esforço despendido neste trabalho teve como objetivo analisar a construção identitária do movimento Occupy Wall Street em dois de seus textos, através das cadeias de equivalência formadas pelos processos referenciais. Muito ainda há a ser explorado a respeito das questões que aqui foram aduzidas, no entanto, acreditamos ter obtido resultados produtivos que ratificam a possibilidade de levar um pouco mais adiante a exploração da natureza discursiva da referenciação e seu caráter político, produzindo implicações para a crítica da linguagem, caminho já sinalizado por Ferreira (2007); e de estreitar a relação entre o social e o discursivo, tão forçosamente apartados ao longo da história da linguística.

Encarar seriamente a afirmação de que todos os objetos se constituem como objetos de discurso (MONDADA \& DUBOIS, 2003; LACLAU \& MOUFFE, [1985] 2015) implica assumir uma postura não-essencialista em relação à construção de identidades sociais, admitindo que a dimensão conflitiva do mundo social, decorrente de sua pluralidade de valores e interesses, interfere diretamente na construção dessas identidades. A relação antagônica é predominantemente performatizada como uma relação agônica, nos termos de Chantal Mouffe (2005). Isso consiste, em certa medida, em um ponto positivo da prática democrática do OWS, visto que, em seu discurso, assumir o outro como um adversário a ser superado, e não como um inimigo a ser banido - ainda que em alguns momentos isso não apareça exatamente dessa forma -, é estar na direção, segundo a autora, de uma democracia radical.

A construção de equivalências, sendo uma ação política necessária e importante, apresenta simultaneamente um aspecto problemático do qual não podemos escapar, em função dos modos como podem se dar a apropriação de significantes vazios na luta política. Embora, como argumenta o próprio Laclau, estes sejam fundamentais ao processo democrático e à luta política, a sua mobilização contém sempre o risco de calar a voz de certas diferenças em favorecimento de outras, ocultando as tensões inerentes a qualquer formação social, criando um efeito homogeneizante e sustentando o mito de um consenso que inexiste na prática, inclusive para significar o próprio movimento e 
instituir um conjunto de fazeres ${ }^{17}$. Ademais, o OWS/99\% está inserido numa sociedade complexa, em que a significação que busca construir para si disputa com a significação que outros discursos constroem a seu respeito, buscando definir a indefinição que ele apresenta - como o discurso da mídia, das autoridades governamentais, etc.

Não devemos esquecer que o poder é inerente à sociedade (MOUFFE, 2005), e que qualquer formação social, dada a própria pluralidade de interesses e valores, encontra obstáculos à promoção de um consenso e de uma coesão de grupo. Os grupos sociais que visam a empreender uma crítica ao sistema político-econômico hegemônico, de modo geral, precisam estar atentos a isso para não recair (sob outras facetas) naquilo para que Zizek (2011) aponta como um discurso de liberdade e igualdade segundo a lógica do novo espírito do capitalismo e sua razão cínica.

\section{REFERÊNCIAS}

AUBERT, F. H. Modalidades de tradução: teoria e resultados. In: Tradterm, ano 5, n. 1: 99-128. São Paulo, SP. 1 sem. 1998.

BURITY, J. Discurso, política e sujeito na teoria de Ernesto Laclau. In:MENDONÇA, D. \& RODRIGUES, L. P. (orgs.). Pós-estruturalismo e teoria do discurso: em torno de Ernesto Laclau. 2. ed. Porto Alegre: EdiPUCRS, 2014.

CARDOSO, Sílvia H. B. A questão da referência: das teorias clássicas à dispersão de discursos. Campinas: Autores Associados, 2003.

CASTELLS, M. Redes de indignação e esperança: movimentos sociais na era da internet. Rio de Janeiro: Zahar, 2013.

CAVALCANTE, M. M. Referenciação: sobre coisas ditas e não-ditas. Fortaleza: Edições UFC, 2011.

CAVALCANTE, T. M. B. M. 2016. “We are the 99\%”: referenciação e equivalência na construção identitária do movimento Occupy Wall Street. Fortaleza, CE. Mestrado Acadêmico em Linguística Aplicada. Universidade Estadual do Ceará, 148 p.

FERREIRA, R. R. Guerra na Língua: mídia, poder e terrorismo. Fortaleza: EdUECE, 2007.

HICKEL, J. (2012). Liberalism and the politics of Occupy Wall Street. In: Anthropology of this century, 4.4 Disponível em:

\footnotetext{
17 Em razão disso, é necessário estar sob vigilância constante dos usos que fazemos da linguagem, buscando sempre novas formas de articulação.
} 
http://eprints.lse.ac.uk/43389/1/Liberalism\%20and\%20the\%20politics\%20of\%20Occup y\%20Wall\%20Street\%20\%28LSERO\%29.pdf. Acesso em: 13 fev. 2014.

KOCH, I. V. G. Referenciação. In: Introdução à Linguística Textual. São Paulo: Contexto, 2015.

LACLAU, E.; MOUFFE, C. (1985) Hegemonia e Estratégia Socialista:por uma política democrática radical.Tradução de Joanildo A. Burity, Josias de Paula Jr. e Aécio Amaral. São Paulo: Intermeios; Brasília: CNPq, 2015. (Coleção Contrassensos).

Post-Marxism without apologies? In: LACLAU, E. New reflections on the revolution of our time. London: Verso, 1990.

LACLAU, E.; MOUFFE, C. (1985) Hegemonia e Estratégia Socialista: por uma política democrática radical.Tradução de Joanildo A. Burity, Josias de Paula Jr. e Aécio Amaral. São Paulo: Intermeios; Brasília: CNPq, 2015. (Coleção Contrassensos).

LACLAU, E. A Razão Populista. Tradução: Carlos Eugênio Marcondes de Moura.São Paulo: Três Estrelas, 2013.

Emancipação e Diferença. Rio de Janeiro: EdUERJ, 2011.

New Reflections on the Revolution of Our Time. London: Verso, 1990.

MARCUSCHI, L. A. Produção textual, análise de gêneros e compreensão. São Paulo: Parábola Editorial, 2008.

Cognição, linguagem e práticas interacionais. Rio de Janeiro: Lucerna. Série Dispersos, 2007.

MATURANA, H. Cognição, ciência e vida cotidiana. Organização e tradução: Cristina Magro, Victor Paredes. Belo Horizonte: Ed. UFMG, 2001.

MENDONÇA, D. Antagonismo como identificação política. Revista Brasilera de Ciencia Política, nº 9. Brasília, p. 205-228, set./dez. 2012.

MONDADA, L.; DUBOIS, D. Construção dos objetos de discurso e categorização: uma abordagem dos processos de referenciação. Tradução Mônica Magalhães Cavalcante. In: CAVAlCANTE, M. M.; BIASI-RODRIGUES, B.; CIULlA e SILVA, A. (Org.). Referenciação. São Paulo: Contexto, 2003, p. 17-52.

MOUFFE, C. On the political. London; New York: Routledge, 2005.

VAN DIJK, T. A. Discurso e contexto: uma abordagem sociocognitiva. Trad . Rodolfo Ilari. São Paulo: Contexto, 2012.

ZIZEK, S. Primeiro como tragédia, depois como farsa. Trad. Maria Beatriz Medina. São Paulo: Boitempo, 2011. 
Beyond Discourse-Analisys. In: LACLAU, E. New Reflections on the Revolution of Our Time. London: Verso, 1990. 